\title{
The Relationship between Academic Performance and Motivation Level in e-Learning among Thailand University Students
}

\author{
Kew Si Na, Sirirat Petsangsri, and Zaidatun Tasir
}

\begin{abstract}
E-learning has been extensively implemented in universities and motivation is one of the important factors contributing the successful learning. However, few studies focus on the relationship between student motivation level and academic performance in e-learning. Therefore, we explored the relationship between motivation and academic achievement among students in Thai universities. 115 social science students filled in an instructional materials motivation survey and the data was analyzed by using SPSS software. The majority of students were found to have upper to medium motivation levels in e-learning. Further, there was a weak, positive correlation between motivation level and academic achievement, but it was not statistically significant. More results are discussed in this paper.
\end{abstract}

Index Terms-Motivation level, academic performance, e-learning, Thailand university.

\section{INTRODUCTION}

E-learning is gradually becoming more used in university to make teaching and learning more effective. It needs instructors to design a motivating e-learning environment to engage students actively in their learning. In fact, motivation is one of the key factors for attracting student attention and interest in learning. Especially, students should have their own drive and be independent to learn at their own pace in e-learning. However, it is a challenge to keep students motivated for the entire learning period [1], although e-learning brings benefits to learning and teaching practices and influences student learning outcomes.

In Thailand, e-learning has become one of the main focuses of national information technology policy in Thailand, set by the Ministry of Science and Technology [2]. This e-learning aims to provide more meaningful and useful learning content and instructional quality [3] to enhance the quality of education. This has resulted in growth in research interest in e-learning in Thailand, including study of student motivation level in e-learning systems [4]. Nonetheless, searching the literature shows that e-learning studies that explore the relationship between motivation and academic performance of students in Thailand university remain limited and this study partly fills this research gap. This

Manuscript received September 22, 2019; revised February 5, 2020.

Kew Si Na and Zaidatun Tasir are with Faculty of Social Science and Humanities, Universiti Teknologi Malaysia, 81310 Johor Bahru, Johor, Malaysia (e-mail: snkew@utm.my,p-zaida@utm.my).

Sirirat Petsangsri is with Faculty of Industrial Education and Technology, King Mongkut's Institute of Technology Ladkrabang, Bangkok, Thailand (e-mail: sirirat.pe@kmitl.ac.th). structure of this paper is: i) Section II includes the study purpose, ii) Section III reviews the literature on e-learning, motivation and related studies, iii) Section IV describes the methodology used, iv) Section V lists the results and they are discussed in Section VI. Finally, we conclude and mention limitations in Section VII.

\section{PURPOSE}

We investigated the relationship between motivation level and academic achievement of the university students in e-learning in Thailand. In particular, we answered these research questions, relating to students in Thailand:

a) What are the ranges of motivation level of students in e-learning?

b) What is the motivation level of students in e-learning in terms of attention, relevance, confidence and satisfaction?

c) What is the relationship between motivation level and student academic achievement in e-learning?

d) What is the relationship between attention and academic achievement in e-learning?

e) What is the relationship between relevance and academic achievement in e-learning?

f) What is the relationship between confidence and academic achievement in e-learning?

g) What is the relationship between satisfaction and academic achievement in e-learning?

\section{LITERATURE REVIEW}

\section{A. E-Learning}

Fee [5] described e-learning as "any learning that involves using the internet or an intranet." Panyajamorn et al. reported that the Thailand government developed a knowledge-based plan under the National Information Technology (IT) policy framework, that aimed to provide wide-spread internet access and to encourage the use of IT for lifelong education [3]. In conjunction with this, e-learning is being progressively integrated into the Thai education system according to the Ministry of Information and Communication Technology [6]. Bhuasiri et al. [7] believe that one of the basics for implementing effective e-learning in developing countries is motivation. This was supported by Harandi's study of the effects of e-learning on student motivation, which concluded that e-learning can affect student motivation [8].

Moreover, according to Kew et al. [9], despite many 
studies of e-learning in Thailand, there is still limited research measuring motivation levels of students in e-learning in Thai universities: most studies concentrated on the acceptance of and readiness for e-learning aspects and the effectiveness of the e-learning program. Consequently, there is a need to examine student motivation levels in e-learning in a Thai context.

\section{B. Motivation}

Motivation is defined as "a theoretical construct to explain the initiation, direction, intensity, persistence, and quality of behavior, especially goal-directed behavior" [10]. On the other hand, Schunk et al. described motivation as "the process whereby goal-directed activity is instigated and sustained" [11] (p. 4). The role of motivation is important, because it impact the way we learn, the things we learn, and the time we want to learn [12]. In addition, it also determines whether a learner persists in a course and his or her performance and engagement level. Therefore, the motivation element cannot be neglected.

In this respect, Keller's Attention Relevance Confidence Satisfaction (ARCS) model is well-known in motivation studies. It helps to create a motivating environment and measure the student motivation level. This model has been significantly adapted in different research contexts (e.g. [9], [13]); it has four components for motivating learning [14], [15]:

1) Attention: attracting attention to the instructional content,

2) Relevance: connecting to learning objectives,

3) Confidence: developing confidence in learning and

4) Satisfaction: making learning in satisfaction status.

\section{Related Studies}

Amrai et al. studied the correlation between academic motivation and academic achievement in 252 Tehran University students, using an academic motivation questionnaire, and showed a positive and significant correlation between academic motivation and academic achievement [16]. Similarly, Becirovic studied the relationship between gender, motivation and achievement of a sample of 185 students and found a statistically significant correlation between achievement and motivation [17].

Another study focused on the relationship between motivation and academic achievement, a 168 student sample showed a significant relationship between academic achievement and intrinsic motivation subscales, for example to know and to experience stimulation [18]. Similarly, Hasan et al. showed that extrinsic motivation and intrinsic motivation had positive impacts on academic performance [19]. However, a study of 280 students, by Makhlough et al., showed that there was no significant relationship between academic motivation and academic performance [20]. These conflicting reports show thate further research is needed to determine the relationship between motivation and academic achievement.

\section{Methodology}

A sample of 115 undergraduate social science students was used - $31(27 \%)$ male and $84(73 \%)$ female. They were distributed among academic years: Year $448 \%$, Year $330 \%$, Year $24.3 \%$, and Year 1 18\%.(Table I)

\begin{tabular}{lll}
\multicolumn{2}{c}{ TABLE I: DEMOGRAPHIC OF RESPONDENTS } \\
\hline Characteristics & $\begin{array}{l}\text { Number of } \\
\text { respondents }\end{array}$ & Percentage (\%) \\
\hline Gender & 31 & 27 \\
Male & 84 & 73 \\
Female & & \\
Year of Study & 21 & 18 \\
Year 1 & 5 & 4.3 \\
Year 2 & 34 & 30 \\
Year 3 & 55 & 48 \\
Year 4 & & \\
\hline
\end{tabular}

The questionnaire used was adapted from the Instructional Materials Motivation Survey (IMMS) [14]. It had both English and Thailand language as this questionnaire was translated into Thai by a native speaker, fluent in English language. The questionnaire had two sections: (i) demographic questions, and (ii) the motivation survey, which had four subscales: Attention (ATT), Relevance (RELE), Confidence (CONF) and Satisfaction (SAT) items. Scale reliability was tested: the Cronbach $\alpha$ coefficient was 0.93 , so the items had relatively high internal consistency.

The data collected from the respondents was exported into Microsoft Excel and analyzed to measure student motivation levels, based on the IMMS scoring guide in Table II. [21] The data was further analyzed using the Statistical Package for the Social Sciences (SPSS) for inferential statistical analysis to answer the research questions.

\begin{tabular}{cc}
\multicolumn{2}{c}{ TABLE II: MOTIVATION LEVELS AND RANGES } \\
\hline Motivation Level & Ranges \\
\hline High Level (HL) & $4.00 \ldots 5.00$ \\
Upper Medium Level (UML) & $3.50 \ldots 3.99$ \\
Medium Level (ML) & $3.00 \ldots 3.49$ \\
Low Level (LL) & $<3.00$ \\
\hline
\end{tabular}

\section{FINDINGS}

\section{A. Ranges of Motivation Level of Students}

Fig. 1 shows the ranges of motivation level of students. 42 $(37 \%)$ students showed upper medium or medium level of motivation in e-learning. It reveals that most of them had moderate motivation level in using e-learning.

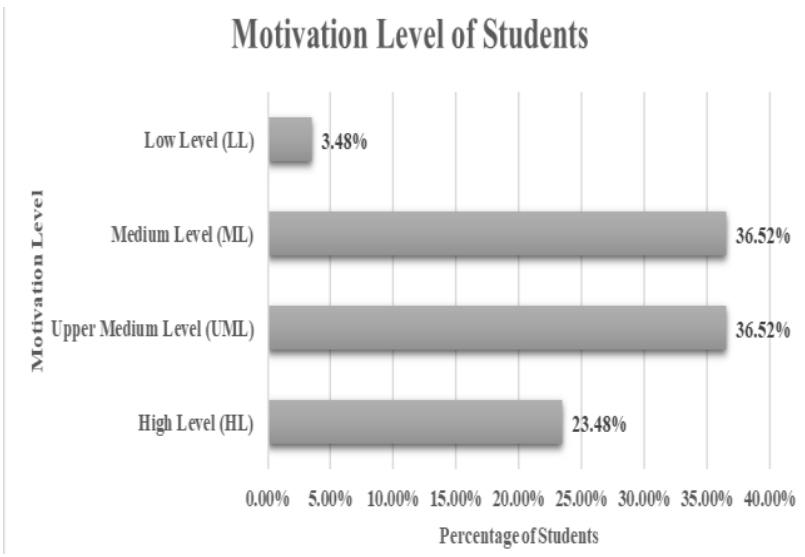

Fig. 1. Ranges of student motivation levels. 


\section{B. Motivation Level of Students in Terms of Attention, Relevance, Confidence and Satisfaction}

Table III indicates that the overall student motivation level is upper medium - mean 3.67. The highest mean of students was satisfaction (mean 3.83), followed by relevance (3.80) and confidence (3.57). The lowest mean was attention (3.47).

\begin{tabular}{cccc}
\multicolumn{4}{c}{ TABLE III: OVERALL STUDENT MOTIVATION LEVEL } \\
\hline Item & $\begin{array}{c}\text { Student Motivation } \\
\text { Level }\end{array}$ & $\begin{array}{c}\text { Class of } \\
\text { motivation level }\end{array}$ \\
\hline ATT (12 items) & 3.5 & .50 & ML \\
RELE (9 items) & 3.8 & .52 & UML \\
CONF (9 items) & 3.576 & .49 & UML \\
SAT (6 items) & 3.83 & .60 & UML \\
Overall (36 items) & $\mathbf{3 . 6 7}$ & $\mathbf{. 4 4 6}$ & UML \\
\hline$*_{n=115}$ & & &
\end{tabular}

\section{Relationship between Motivation Level and Academic Performance}

The normality test showed the significance of motivation level was 0.205 and of academic performance was 0.06 and was normally distributed. In this regard, Pearson's Correlation test was used. Table IV shows that there was a weak, positive correlation between motivation level and academic achievement score, but it was not statistically significant $(r s=.143, p=.127)$.

TABLE IV: PEARSON'S CORRELATION TEST OF THE RELATIONSHIP BETWEEN MOTIVATION LEVEL AND ACADEMIC PERFORMANCE

\begin{tabular}{llll}
\hline & & AcaPerf & Mot \\
\hline AcaPerf & $\begin{array}{l}\text { Pearson } \\
\text { Correlation }\end{array}$ & 1 & 0.143 \\
& Sig. (2-tailed) & & \\
& N & 115 & 0.127 \\
Mot & Pearson & 0.143 & 115 \\
& Correlation & & 1 \\
& Sig. (2-tailed) & 0.127 & \\
& N & 115 & 115 \\
\hline
\end{tabular}

\section{Relationship between Attention and Academic}

\section{Performance}

A normality test showed the significance of attention was 0.00 and academic performance of students was 0.06 . It then confirms that it is not normally distributed. In this regard, Spearman's Correlation test was used. Table V shows a weak, positive correlation between attention and academic achievement score, but it was not significant ( $\mathrm{rs}=0.152$, $p=0.105)$.

TABLE V: SPEARMAN's CORRELATION TEST OF THE RELATIONSHIP BETWEEN ATTENTION AND ACADEMIC PERFORMANCE OF STUDENTS

\begin{tabular}{|c|c|c|c|c|}
\hline & & & AcaPerf & ATT \\
\hline \multirow[t]{6}{*}{$\begin{array}{l}\text { Spearman's } \\
\text { rho }\end{array}$} & AcaPerf & $\begin{array}{l}\text { Correlation } \\
\text { Coefficient }\end{array}$ & 1.000 & 0.152 \\
\hline & & $\begin{array}{l}\text { Sig. } \\
\text { (2-tailed) }\end{array}$ & & 0.105 \\
\hline & & $\mathrm{N}$ & 115 & 115 \\
\hline & ATT & $\begin{array}{l}\text { Correlation } \\
\text { Coefficient }\end{array}$ & 0.152 & 1.000 \\
\hline & & $\begin{array}{l}\text { Sig. } \\
\text { (2-tailed) }\end{array}$ & 0.105 & \\
\hline & & $\mathrm{N}$ & 115 & 115 \\
\hline
\end{tabular}

\section{E. Relationship between Relevance and Academic Performance of Students}

Spearman's Correlation test for normality showed that the significance of relevance was 0.04 and academic performance was 0.06 , confirming that it was not normally distributed. Table VI demonstrated that there was a weak, positive correlation between relevance and academic achievement score, but it was not significant ( $\mathrm{rs}=0.133$, $p=0.158)$.

TABLE VI: SPEARMAN'S CORRELATION TEST OF THE RELATIONSHIP BETWEEN RELEVANCE AND ACADEMIC PERFORMANCE OF STUDENTS

\begin{tabular}{|c|c|c|c|c|}
\hline & & & AcaPerf & RELE \\
\hline \multirow[t]{6}{*}{$\begin{array}{l}\text { Spearman's } \\
\text { rho }\end{array}$} & \multirow[t]{3}{*}{ AcaPerf } & $\begin{array}{l}\text { Correlation } \\
\text { Coefficient }\end{array}$ & 1.000 & 0.133 \\
\hline & & Sig. (2-tailed) & & 0.158 \\
\hline & & $\mathrm{N}$ & 115 & 115 \\
\hline & \multirow[t]{3}{*}{ RELE } & $\begin{array}{l}\text { Correlation } \\
\text { Coefficient }\end{array}$ & 0.133 & 1.000 \\
\hline & & Sig. (2-tailed) & 0.158 & \\
\hline & & $\mathrm{N}$ & 115 & 115 \\
\hline
\end{tabular}

\section{F. Relationship between Confidence and Academic Performance of Students}

Spearman's Correlation test showed that the significance of confidence was 0.00 and academic performance was 0.06 , and that it was not normally distributed. Table VII indicated a weak, positive correlation between confidence and academic achievement score, which was significant $(r s=$ $0.197, p=0.035)$.

TABLE VII: SPEARMAN'S CORRELATION TEST OF THE RELATIONSHIP BETWEEN CONFIDENCE AND ACADEMIC PERFORMANCE OF STUDENTS

\begin{tabular}{|c|c|c|c|c|}
\hline & & & AcaPerf & CONF \\
\hline \multirow{8}{*}{$\begin{array}{l}\text { Spearman's } \\
\text { rho }\end{array}$} & AcaPerf & Correlation & 1.000 & $.197^{*}$ \\
\hline & & Coefficient & & \\
\hline & & Sig. (2-tailed) & & 0.035 \\
\hline & & $\mathrm{N}$ & 115 & 115 \\
\hline & CONF & Correlation & $.197^{*}$ & 1.000 \\
\hline & & Coefficient & & \\
\hline & & Sig. (2-tailed) & 0.035 & \\
\hline & & $\mathrm{N}$ & 115 & 115 \\
\hline
\end{tabular}

\section{G. Relationship between Satisfaction and Academic Performance}

Pearson's Correlation test for normality showed that the significance of satisfaction and academic performance was 0.06 and it was normally distributed. Table VIII shows a weak, positive correlation between satisfaction and academic achievement score, but it was not significant ( $r s=0.1$, $p=0.32$ ).

TABLE VIII: PEARSON'S CORRELATION TEST OF THE RELATIONSHIP BETWEEN SATISFACTION AND ACADEMIC PERFORMANCE OF STUDENTS

\begin{tabular}{llll}
\hline & & AcaPerf & SAT \\
\hline AcaPerf & Pearson Correlation & 1 & 0.10 \\
& Sig. (2-tailed) & & 0.322 \\
& N & 115 & 115 \\
SAT & Pearson Correlation & 0.10 & 1 \\
& Sig. (2-tailed) & 0.322 & \\
& $\mathrm{~N}$ & 115 & 115 \\
\hline
\end{tabular}

\section{DISCUSSION}

The majority of students had moderate motivation levels 
for using e-learning. It can be assumed that these students desired to use e-learning. Bekele [22] pointed out that motivation is one of the keys to the success of online courses. Hence, there is a need to implement e-learning in Thai universities, so that these students can continuously use e-learning to learn and complete their tasks. Following in depth examination, the satisfaction category, with the highest mean motivation, was found to contribute the most to student motivation levels. This was because the learning materials and activities in e-learning made students satisfied and achieved their learning goals and expectations. The second highest mean was the relevance category, which also contributed to the motivation level of students. We believe that students found relevant and suitable learning materials and activities in e-learning, resulting in the upper medium level of motivation. The lowest mean category was attention: we attributed this to a relatively boring design of the materials and activities. Therefore, in order to draw the attention of students, it is suggested that the more effort should be put into design of learning materials and activities and they are considered carefully. El-Seoud et al. [4] also highlighted the use of interactive features of e-learning to enhance student motivation.

This study sheds light on this aspect by presenting the outcomes of the relationship between overall motivation level and academic performance: it showed a weak, positive correlation between motivation level and academic achievement score, although it was not significant at $p=$ 0.127 , $(r s=0.143)$, there was a positive but weak relationship between motivation level and academic performance. Our result is quite similar to others reported in the literature [16]-[18], which found that there is a relationship between motivation level and academic achievement.

Moreover, this study investigated the relationship between motivation level and academic performance in more detail, i.e. in terms of attention, relevance, confidence and satisfaction. We found that there is a weak, positive correlation in academic performance between attention, relevance, confidence and satisfaction. However, we found a significant difference between academic performance and confidence of students. We confirmed the importance of a motivation element in term of confidence in e-learning that can affect the academic performance of social science students. Therefore, instructors should design learning materials, integrated with confidence elements for students, as they can help to enhance learning outcomes. For example, giving instruction, increasing student belief in their competence and building a positive expectation for success are some basic tactics suggested in Keller's ARCS model [23].

\section{CONCLUSIONS AND LIMITATIONS}

E-learning plays an important role because the learning activities and materials in e-learning influence student motivation levels and their academic performance. In particular, these materials used in e-learning can capture student attention and connect to students, which in turn boosts student confidence and makes students feel satisfied with positive reinforcements or rewards [24]. This research has contributed towards the body of knowledge of the relationship between academic performance and motivation level of Thai social science students in e-learning. Nonetheless, this study had some limitations. For example, the sample size was not large enough to generalize the result to all situations and only one instrument was used to study the relationship between academic performance and motivation level. Therefore, in the future research, this research should involve more respondents from different universities and more instruments should be used to gain more insight on the relationship between student motivation and academic performance.

\section{CONFLICT OF INTEREST}

We declare no conflict of interest.

\section{AUTHOR CONTRIBUTIONS}

All authors made contributions to all aspects of this paper.

\section{ACKNOWLEDGMENT}

We thank Assoc. Prof. Jittavee Khlaisang, Assist. Prof. Praweenya Suwannatthachote from Chulalongkorn University and Assoc.Prof. Nattakorn Songkham from King Mongkut's Institute of Technology Ladkrabang, who assisted with data collection.

\section{REFERENCES}

[1] I. Ghergulescu and C. H. Muntean, "Assessment of motivation in gaming-based e-learning," in Proc. the IADIS International Conference on WWW/Internet, 2000, p. 71.

[2] Ministry of Science and Technology, "Executive summary: Thailand information and communication technology (ICT) policy framework (2011-2020)," Bangkok: Ministry of Science and Technology, 2011,

[3] T. Panyajamorn et al, "Effectiveness of e-learning design and affecting variables in Thai public schools," Malaysian Journal of Learning and Instruction, vol. 15, no. 1, pp. 1-34, 2018

[4] M. S. A. El-Seoud, I.A. T. F. Taj-Eddin, N. Seediek, M. M. El-Khouly, and A. Nossier, "E-learning and students' motivation: A research Study on the effect of e-learning on higher education," International Journal of Emerging Technologies in Learning, pp. 19-26, 2014.

[5] K. H. Fee, Delivering e-Learning: A Complete Strategy for Design Application and Assessment, 2005, London and Philadelphea: Kogan Page.

[6] Ministry of ICT, "Outcomes of evaluating the implementation of Thailand ICT policy 2001-2010(IT2010),” Bangkok: Silpakorn, 2008.

[7] W. Bhuasiri, O. Xaymoungkhoun, H. J. Zo, R. R. J. Jeung, and P. C. Andrew, "Critical success factors for e-learning in developing countries: A comparative analysis between ICT experts and faculty," Computers \& Education, vol. 58, no. 2, pp. 843-855, 2012

[8] S. R. Harandi, "Effects of e-learning on students' motivation," Procedia-Social and Behavioral Sciences, vol. 181, pp. 423-430. 2015.

[9] S. N. Kew, S. Petsangsri, T. Ratanaolarn, and Z. Tasir, "Examining the motivation level of students in e-learning in higher education institution in Thailand: A case study," Education and Information Technologies, vol. 23, no. 6, pp. 2947-2967, 2018.

[10] J. Brophy, Motivating Students to Learn, New York, NY: Routledge, 2010.

[11] D. H. Schunk, P. R Pintrich, and J. L. Meece, Motivation in Education: Theory, Research, and Applications, Upper Saddle River, NJ: Pearson/Merrill Prentice Hall, 2008.

[12] D. H. Schunk and E. L. Usher, "Social cognitive theory and motivation," Oxford Library of Psychology. The Oxford Handbook of Human Motivation, pp. 13-27, New York, NY, US: Oxford University Press, 2012.

[13] R. Small, N. Zakaria, and H. El-Figuigui, "Motivational aspects of information literacy skills instruction in community college libraries," College \& Research Libraries, vol. 65, no. 2, pp. 96-122, 2004.

[14] J. M. Keller, "The use of the ARCS model of motivation in teacher training," Aspects of Educational Technology: Volume XVII: Staff 
Development and Career Updating, pp. 140-145, London: Kogan, 1984.

[15] J. M. Keller, "Development and use of the ARCS model of motivational design," Journal of Instructional Development, vol. 10, no. 3, pp. 2-10, 1987a.

[16] K. Amrai, S. E. Motlagh, H. A. Zalani, and H. Parhon, "The relationship between academic motivation and academic achievement students," Procedia-Social and Behavioral Sciences, vol. 15, pp. 399-402, 2011

[17] S. Becirovic, "The relationship between gender, motivation and achievement in learning English as a foreign language," European Journal of Contemporary Education, vol. 6, no. 2, pp. 210-220, 2018.

[18] G. Eymur and Ö. Geban, "An investigation of relationship between motivation and academic achievement of pre-service chemistry teachers," Egitim ve Bilim, vol. 36, no. 161, p. 246, 2011.

[19] A. Hasan, A. Imran, A. K. Muhammad, and H. Kashif, "A study of university students' motivation and its relationship with their academic performance," International Journal of Business and Management, vol. 5 , no. 4 , pp. 80-88, 2010.

[20] A. Makhlough, H. Siamian, F. N. Asrami, M. Khademloo, and H. Esmaeili, "The relationship between academic motivation and academic performance among students at Mazandaran University of Medical Sciences in 2014," International Journal of Humanities and Cultural Studies, pp. 1419-1426, 2014.

[21] B. Huang and K. F. Hew, "Measuring learner's motivation level in massive open online courses," International Journal of Information and Education Technology, vol. 6, no. 10, pp. 759-764, 2016.

[22] T. A. Bekele, "Motivation and satisfaction in internet-supported learning environments: A review," Educational Technology and Society, vol. 13, no. 2, pp. 116-127, 2010.

[23] J. M. Keller and K. Suzuki, "Learner motivation and e-learning design: A multinationally validated process," Journal of Educational Media, vol. 29, no. 3, pp. 229-239, 2004.

[24] J. M. Keller, Motivational Design for Learning and Performance: The ARCS Model approach, New York: Springer, 2010.

Copyright $(\odot 2020$ by the authors. This is an open access article distributed under the Creative Commons Attribution License which permits unrestricted use, distribution, and reproduction in any medium, provided the original work is properly cited (CC BY 4.0).

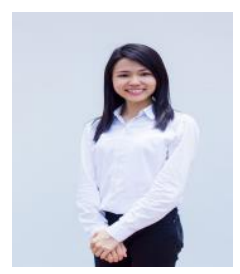

Kew Si Na is a senior lecturer at Universiti Teknologi Malaysia, Malaysia. She was born in Malaysia on 28th February 1991. She received a bachelor in TESL at Universiti Teknologi Malaysia in 2015 and completed her $\mathrm{PhD}$ studies in educational technology at Universiti Teknologi Malaysia in 2018. She received several great awards during her $\mathrm{PhD}$ convocation. Her research interests are teaching and learning, teaching English as a second language (TESL), technology enhanced language learning (TELL), computer assisted language learning (CALL), online teaching and learning, and learning analytics (LA).

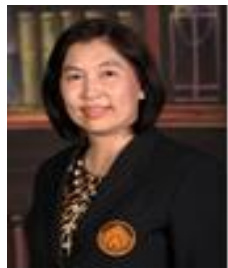

Sirirat Petsangsri has a doctor of education in instructional design and technology, School of Education, University of Pittsburgh, USA. Currently she is the head of Industrial Education Department, Faculty of Industrial Education and Technology, King Mongkut's Institute of Technology Ladkrabang, Thailand. Her research focusses on educational technology enhanced learning, motivation in e-learning, blended learning environments and flipped classroom.

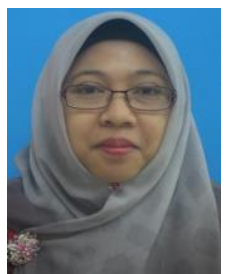

Zaidatun Tasir is a professor of educational technology at the Department of Educational Science, Maths and Creative Multimedia, School of Education, Faculty of Social Science \& Humanities, Universiti Teknologi Malaysia. She was the chairperson of Malaysian Deans of Graduate Schools Council (MyDEGS) 2016-2019. She was also the dean of School of Graduate Studies, UTM and a research group member of Creative and Innovative Technology in Education (CITE) under Smart Digital Community Research Alliance. Her research interests and expertise include design and development of computer and web-based instructions, multiple intelligence through computer-based instruction, problem-based learning through technology, social networking tools in education, and online social learning model. 